\title{
Four types of scrapie in goats differentiated from each other and bovine spongiform encephalopathy by biochemical methods
}

\author{
Jan P. M. Langeveld ${ }^{1 *}\left(\mathbb{D}\right.$, Laura Pirisinu², Jorg G. Jacobs ${ }^{1}$, Maria Mazza ${ }^{3}$, Isabelle Lantier ${ }^{4}$, \\ Stéphanie Simon ${ }^{5}$, Olivier Andréoletti ${ }^{6}$, Cristina Acin ${ }^{7}$, Elena Esposito ${ }^{2}$, Christine Fast ${ }^{8}$, Martin Groschup ${ }^{8}$, \\ Wilfred Goldmann ${ }^{9}$, John Spiropoulos ${ }^{10}$, Theodoros Sklaviadis ${ }^{11}$, Frederic Lantier ${ }^{4}$, Loukia Ekateriniadou ${ }^{12}$, \\ Penelope Papasavva-Stylianou ${ }^{13}$, Lucien J. M. van Keulen ${ }^{1}$, Pier-Luigi Acutis ${ }^{3}$, Umberto Agrimi ${ }^{2}$, Alex Bossers ${ }^{1}$ \\ and Romolo Nonno ${ }^{2}$
}

\begin{abstract}
Scrapie in goats has been known since 1942, the archetype of prion diseases in which only prion protein (PrP) in misfolded state $\left(\mathrm{PrPSC}^{\mathrm{SC}}\right.$ ) acts as infectious agent with fatal consequence. Emergence of bovine spongiform encephalopathy (BSE) with its zoonotic behaviour and detection in goats enhanced fears that its source was located in small ruminants. However, in goats knowledge on prion strain typing is limited. A European-wide study is presented concerning the biochemical phenotypes of the protease resistant fraction of $\mathrm{PrPS}^{\mathrm{Sc}}$ (PrPres) in over thirty brain isolates from transmissible spongiform encephalopathy (TSE) affected goats collected in seven countries. Three different scrapie forms were found: classical scrapie (CS), Nor98/atypical scrapie and one case of CH1641 scrapie. In addition, CS was found in two variants - CS-1 and CS-2 (mainly Italy) — which differed in proteolytic resistance of the PrPres N-terminus. Suitable Prpres markers for discriminating CH1641 from BSE (C-type) appeared to be glycoprofile pattern, presence of two triplets instead of one, and structural (in)stability of its core amino acid region. None of the samples exhibited BSE like features. BSE and these four scrapie types, of which CS-2 is new, can be recognized in goats with combinations of a set of nine biochemical parameters.
\end{abstract}

\section{Introduction}

Prion diseases or transmissible spongiform encephalopathies (TSEs) are lethal neurological infections in mammals caused by prions from either sporadic, familial or transmissible origin [1,2]. Since the 1980 s, a zoonotic form of the disease emerged in cattle as bovine spongiform encephalopathy (BSE, C-type) through consumption of contaminated meat and bone meal (MBM) [3, 4]. BSE was detected in the United Kingdom but later also in and outside of Europe although less frequently. In 1995, a human variant form of human Creutzfeldt-Jakob disease (vCJD) emerged with phenotypic similarities to BSE

\footnotetext{
${ }^{*}$ Correspondence: jan.langeveld@wur.nl

${ }^{1}$ Wageningen BioVeterinary Research (WBVR), Wageningen University \&

Research, Houtribweg 39, 8221RA Lelystad, The Netherlands

Full list of author information is available at the end of the article
}

$[5,6]$. A decennium later, TSE in cattle was differentiated by Western blotting in three types of BSE, C-type BSE and rare cases of $\mathrm{H}$ - and L-type BSE [7-9]. Measures to prevent continual feeding of livestock with MBM circulation have led to the near disappearance of BSE and VCJD worldwide. Critical herein were also diagnostic post mortem tests with prion protein (PrP) specific antibodies that reveal the presence of protease resistant prion material that is composed of malformed $\operatorname{PrP}\left(\operatorname{PrP}^{\mathrm{Sc}}\right)$ [10]. Awareness and strict surveillance of prion infections remain necessary, not only because of the zoonotic and epizootic risks of BSE but also other forms of TSE with different transmittabilities such as chronic wasting disease (CWD) in cervids in North America and South Korea, and newly discovered TSEs in cervids in Norway and camelids in Algeria [11-13].

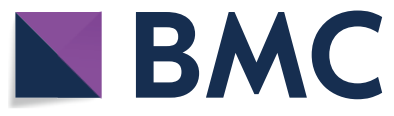

(c) The Author(s) 2019. This article is distributed under the terms of the Creative Commons Attribution 4.0 International License (http://creativecommons.org/licenses/by/4.0/), which permits unrestricted use, distribution, and reproduction in any medium, provided you give appropriate credit to the original author(s) and the source, provide a link to the Creative Commons license, and indicate if changes were made. The Creative Commons Public Domain Dedication waiver (http://creativecommons.org/ publicdomain/zero/1.0/) applies to the data made available in this article, unless otherwise stated. 
Like other infectious agents, prions also exist as strains. Their transmissibility depends uniquely and largely on the amino acid sequence of normal cellular $\operatorname{PrP}\left(\operatorname{PrP}^{\mathrm{C}}\right)$, and possibly on host factors during conversion of $\operatorname{PrP}^{\mathrm{C}}$ to $\operatorname{PrP}^{\mathrm{Sc}}$ [14]. Strain characteristics are phenotypical properties such as incubation time, lesion profile, and variations in deposition and molecular features of $\operatorname{PrP}^{\mathrm{Sc}}$. Multiple strains from scrapie in sheep have been described in rodent bioassays, while bovine BSE behaves as a single strain $[1,5,15]$.

However, in goats strain typing efforts have rarely been reported [16-18]. While scrapie in sheep is known to have existed for centuries, there are no indications that under natural conditions other species are infected by scrapie except goats. The source of the BSE epidemic is still uncertain, but plausible explanations are that it has evolved from small ruminant scrapie or from a sporadic case of BSE in cattle $[3,9]$. Sheep and goats are known to be susceptible to BSE, but in the field only two cases in goats have been reported and these most probably originated from ingesting BSE contaminated feed [19-21].

Before deciding to carry out strain typing bioassays in rodents with their long lasting incubation times, ELISA and Western blotting (WB) with infected brain samples are important to rapidly classify scrapie like TSE types ${ }^{1}$ and to exclude the presence of BSE [22-30]. In sheep, scrapie occurs in different biochemical types such as classical scrapie ${ }^{2}$ (CS), atypical/Nor98 scrapie (AS) and a rare form of CS, CH1641 scrapie. Proteolytic digestion with proteinase $\mathrm{K}(\mathrm{PK})$ of the $\mathrm{PrP}^{\mathrm{Sc}}$ aggregate and its subsequent unfolding and dissociation are essential for binding by $\operatorname{PrP}$ site-specific antibodies. CH1641 scrapie exhibits similarities with BSE since in both types distinct $\mathrm{N}$-terminal $\operatorname{PrP}$ epitopes are protease sensitive [31]. In addition, mixtures of TSE forms could be present in a single animal, which hamper recognition of low BSE levels [32].

During 2004-2014, we collected over seventy TSE goat brain samples from seven European countries based on various criteria such as tissue quality, geographical distribution, breed, PRNP genotype. From this unique collection, over thirty goat TSE isolates from seven EU countries have been subjected to biochemical TSE-typing. These samples were probed by ELISA and Western

\footnotetext{
1 "TSE type" is used for phenotypic observations in infected tissues based on microscopic or test tube experiments. "Strain type" is used as the outcome from passaging of infected tissue in another host, usually rodents such as inbred mouse or bank vole lines, or transgenic mice expressing PrP from another species.

2 In biochemical terms, classical TSEs yields in Western blot analyses a triplet of $\mathrm{PrP}^{\mathrm{res}}$ bands consisting of a di-, mono-, and non-glycosylated (resp. D, M and N) PrP fragment of similar amino acid sequence. For clarity in the use of uppercase N: non-glycosylated will be written with a regular capital $\mathrm{N}$ and amino terminus with the italics description $\mathrm{N}$-terminus.
}

blotting for the presence of different sequence domains in $\mathrm{PrP}^{\mathrm{Sc}}$ under different conditions of pre-treatment and proteolysis when preparing its proteinase $\mathrm{K}(\mathrm{PK})$ resistant domain $\left(\mathrm{PrP}^{\mathrm{res}}\right)$. Samples such as CS, AS, BSE and CH1641 scrapie served as references. These materials are also under strain typing investigation by rodent bioassays.

\section{Materials and methods \\ Antibodies}

PrP-specific monoclonal antibodies (mAbs) used in this study were L42 and P4 (R-Biopharm, Germany), Sha31, SAF84, SAF34 and Bar224 (SpiBio, France), and 12B2 and 9A2 (WBVR, Lelystad, Netherlands). The mapped epitope amino acid sequences (sheep PrP numbering, [33]) determined by immobilized multi-peptide analyses are: 70QPHGGGW76 (SAF34), 93WGQGGSH99 (P4), 93WGQGG97 (12B2), 102WNK104 (9A2), 144FGSNDYEDRYYR154 (Bar224), 148YEDRYY153 (L42), 148YEDRYYRE155 (Sha31), and 167YRPVDQY172 (SAF84) [34-38].

\section{Animals and tissues}

During 2004-2012, we collected over seventy TSE goat brain samples from seven European countries fitting the EU rules EC No. 999/2001 for TSE surveillance. As study samples a selection of 32 of these field cases was chosen together with two confirmed negatives (study codes G15, G17), and three experimentally infected goats: orally challenged with goat scrapie (F11), goat intra-cerebrally (i.c.) inoculated with sheep scrapie (F2) and i.c. inoculated with bovine BSE (ic-gtBSE1) (Table 1). The selection was based on criteria such as tissue quality, genotype, broad geographical distribution, and potential type variation. Tissues used consisted mainly of brain stem obtained at slaughterhouses or at euthanasia of experimentally infected animals. The national identity code, country of origin, breed, age and $\operatorname{PrP}$ genotype of the samples were recorded. Only the samples from United Kingdom, Netherlands, and two Greek cases (G13, G16) originated from single holdings.

In addition, infected goat brain materials from other studies were investigated derived from animals infected i.c. with scrapie $(n=6)$ and orally or i.c. with BSE $(n=9)[39,40]$. As occasional reference controls were included experimental sheep and goat BSE, ovine CS $(n=2)$, bovine BSE, caprine AS, and i.c. raised CH1641 material from sheep $(n=2)$ and goat, and an ovine CH1641-like field case (see Additional file 1). The animal experiments to obtain these materials were performed at WBVR according to European directive 2010/63/ EU and in agreement with the Dutch Central Authority 
Table 1 Goat sample codes and details and final outcome of the TSE typing study

\begin{tabular}{|c|c|c|c|c|c|c|}
\hline Study code & Country & Identity \# & Breed [region] $^{\mathrm{a}}$ & Age (year) ${ }^{a}$ & Genotype $^{\mathbf{b}}$ & Molecular TSE-type \\
\hline \multicolumn{7}{|c|}{ STUDY CASES } \\
\hline 12 & $\mathrm{IT}$ & $114921 / 1 / 1$ & Camosciata [Piedmond] & 10 & $240 \mathrm{PP}$ & CS-2 \\
\hline 13 & & $121429 / 1 / 1$ & Meticcia [Sicily] & 5 & $240 P P$ & CS-2 \\
\hline 14 & & $128710 / 1 / 1$ & Saanen [Lombardy] & 3 & $211 \mathrm{QR}, 240 \mathrm{PS}$ & CS-2 \\
\hline 15 & & $17646 / 1 / 1$ & Meticcia [Sicily] & 5 & $240 P P$ & CS-2 \\
\hline 17 & & $85788 / 1 / 1$ & Meticcia [Sicily] & $>1.5$ & $240 \mathrm{PP}$ & CS-2 \\
\hline 19 & & $85792 / 1 / 1$ & Meticcia [Sicily] & 6 & 143HR, 240PS & CS-2 \\
\hline 111 & & $117463 / 1 / 1$ & Meticcia [Emilia-Romagna] & 9 & $240 P S$ & $\mathrm{CS}-2$ \\
\hline 112 & & $144508 / 1 / 1$ & Alpina [Apulia] & 5 & 240PS & CS-2 \\
\hline 115 & & $87016 / 1 / 1$ & Meticcia [Campania] & 6 & $154 \mathrm{RH}, 240 \mathrm{PS}$ & AS \\
\hline N1 & $\mathrm{NL}$ & 577277 & Dwarf goat [Limburg] & $2-3$ & 143HR, 240PS & CS-1 \\
\hline N2 & & $586632-32$ & Dwarf goat [Limburg] & $?$ & $240 P P$ & CS-1 \\
\hline N3 & & $586632-33$ & Dwarf goat [Limburg] & $?$ & 143HR, 240PS & CS-1 \\
\hline$F 2^{*}$ & $\mathrm{FR}$ & CP40 & Saanen [INRA] & 4 & 240PS & CS-1 \\
\hline F3 & & CDP1028 & Saanen [Poitou] & 5 & $240 \mathrm{PP}$ & CS-1 \\
\hline F6 & & CP2119 & Saanen [Charentes] & $3-4$ & 240PS & CS-1 \\
\hline $\mathrm{F} 10$ & & $C P / 2143$ & Alpine [Limousin] & $3-4$ & $240 P S$ & CS-1 \\
\hline $\mathrm{F} 11^{*}$ & & CP2154 & Saanen [Poitou] & 4 & $142 \mathrm{IM}, 240 \mathrm{PP}$ & $\mathrm{CS}-1$ \\
\hline F14 & & CP9041 & Alpine [Poitou] & 6 & $142 \mathrm{IM}, 240 \mathrm{PS}$ & $\mathrm{CS}-1^{\mathrm{C}}$ \\
\hline F16 & & CP9135 & Alpine [Indre] & 6 & $240 P S$ & CS-2 \\
\hline ic-gtBSE1* & & $\mathrm{CH} 1075$ & Saanen [INRA] & $?$ & $211 R Q, 240 P S$ & BSE \\
\hline $\mathrm{S} 2$ & $\mathrm{SP}$ & $C-163 P$ & Alpine [Asturia] & 6 & 240PS & CS-1 \\
\hline S3 & & $C-645 P$ & Crossbreed [Aragon] & 4 & $240 P P$ & CS-1 \\
\hline G2 & GR & 1663 & Capra prisca [Macedonia] & $?$ & $240 P P$ & $\mathrm{CS}-1^{\mathrm{C}}$ \\
\hline G3 & & 1676 & Capra prisca [Macedonia] & 4 & $143 \mathrm{HR}, 240 \mathrm{PP}$ & CS-1 \\
\hline G11 & & GR005 & Capra prisca [Larissa] & 6 & $211 \mathrm{RQ}, 222 \mathrm{QK}$ & CS-1 \\
\hline G12 & & GR177 & Capraprisca [Larissa] & 4 & 222QK & $<^{c}$ \\
\hline G13 & & GR018 & Capra prisca [Larissa] & 5 & wt & CS-1 \\
\hline G14 & & GR055 & Capra prisca [loannina] & 4 & wt & CS-1 \\
\hline G15 & & GR195 & Capra prisca [Kozani] & 2.5 & $222 \mathrm{QK}$ & NEG \\
\hline G16 & & GR091 & Capra prisca [Thessaloniki] & 2 & wt & CS-1 \\
\hline G17 & & GR247 & Capra prisca [Evros] & 4.6 & $222 \mathrm{QK}$ & NEG \\
\hline $\mathrm{C} 1$ & CYP & Zyp13 & Damascus [Nicosia] & 4 & $240 \mathrm{PP}$ & CS-1 \\
\hline $\mathrm{C} 2$ & & Zyp21 & Damascus [Nicosia] & 5 & $240 P P$ & CS-1 \\
\hline $\mathrm{C} 3$ & & Zyp27 & Damascus [Nicosia] & 3 & wt, 240PP & CS-1 \\
\hline UK-A2 & UK & G08-1475 & Anglo-NubianxSaanen [?] & 4 & 127GS, 240PP & CS-1 \\
\hline UK-B2 & & G08-1469 & Anglo-NubianxSaanen [?] & 8 & $127 \mathrm{GS}, 240 \mathrm{PP}$ & $\mathrm{CS}-\mathrm{CH} 1641$ \\
\hline UK-C2 & & G08-1460 & Anglo-NubianxSaanen [?] & 9 & 127GS, 240PP & CS-1 \\
\hline UK-D2 & & G08-1446 & Anglo-NubianxSaanen [?] & 7 & $211 R Q, 240 P P$ & $<^{c}$ \\
\hline
\end{tabular}

Study codes will be used in the text reflecting the country of origin, I for Italy, N Netherlands, F France, S Spain, G Greece, C Cyprus, UK United Kingdom. From single holdings were only the cases from Netherlands, UK and Greek cases G13 and G16. Symbols: *, obtained after experimental infections (see "Materials and methods"). The specific tests performed on the samples, the PrPres content of the sample (when analysed in Triplex-WB) are presented in Additional file 2.

a INRA, Institut National de la Recherche Agronomique. ?= region of origin or age not disclosed or not known.

b Genotype as defined by specific polymorphic codon positions in the goat PRNP gene. Wild type (wt) is defined as follows: $127 \mathrm{GG}, 142 \mathrm{ll}, 143 \mathrm{RR}, 154 \mathrm{RR}, 211 \mathrm{RR}$, 222QQ, 240SS. Unless wt genotype, only the codon positions that differ from homogenous wild type are shown.

c Samples F14 and G2: probably CS-1. F14 too weak for Triplex-WB and ISS-PK methods, G2 too little amount for distribution. G12 and UK-D2: late samples, only analysed by Triplex-WB, too weak signal for analysis. 
for Scientific Procedures on Animals, permit number AVD401002016522.

Fifty percent macerates in water were prepared under TSE sterile conditions. Samples were weighed, immersed in an equal part of water, minced, and left for $18 \mathrm{~h}$ at $4{ }^{\circ} \mathrm{C}$. Material was ground in a Pyrex glass Dounce to a homogenous paste, further forced several times through a $19 \mathrm{G}$ needle, and finally stored in aliquots at $-80{ }^{\circ} \mathrm{C}$. These macerates were dispatched to the participating laboratories. Depending on the analysis and the timely availability of tissue, the set of samples used per study differed (see Additional file 2).

\section{CEA-ELISA (performed at CEA: Commissariat à l'énergie atomique et aux énergies alternatives)}

A discriminatory ELISA for detecting BSE in small ruminants followed procedures as described [28]. Each sample was treated in two ways which is proteinase-K (PK) digestion in normal condition A (Biorad proprietary detergent and chaotrope concentrations, $0.04 \mathrm{mg} \mathrm{mL}^{-1}$ $\mathrm{PK})$ and denaturing condition $\mathrm{A}^{\prime}(5 \%[\mathrm{w} / \mathrm{v}] N$-lauroylsarcosine sodium salt, $5 \%[\mathrm{w} / \mathrm{v}]$ sodium dodecyl sulphate, $0.11 \mathrm{mg} \mathrm{mL}^{-1} \mathrm{PK}\left(\mathrm{A}^{\prime} / \mathrm{A}\right)$. Negatives do not show a $\operatorname{PrP}^{\text {res }}$ signal. The following normalised ratios $\mathrm{A}^{\prime} / \mathrm{A}$ are indicative for CS, BSE and AS respectively $>1.43$, between $0.78-1.43$ and below 0.78 .

\section{ISS-WB procedure for discrimination between classical scrapie and BSE (performed at ISS: Istituto Superiore di Sanità)}

To discriminate between classical scrapie and BSE, the ISS discriminatory Western blot procedure (ISS-WB) was used. This test uses $0.2 \mathrm{mg} \mathrm{mL}^{-1} \mathrm{PK}$ for digestion and

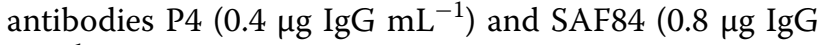
$\mathrm{mL}^{-1}$ ) for detection. Data were collected with a chemo luminescence imager (VersaDoc, Bio-Rad) and quantified as in TSE EU Reference Laboratory manual. Two decisive cut-off values for BSE are applied: in BSE samples the P4/SAF84 ratios should be $<0.5$ and molecular mass of the non-glycosylated $\operatorname{PrP}^{\text {res }}$ band (N, see footnote 2 for the triplet terms N, M and D) based on SAF84 $<0.5 \mathrm{kDa}$ compared to that of internal control (sample I11) [41, 42].

\section{IZSTO-WB procedure for detection of Nor98/atypical scrapie (AS) (performed at IZSTO: Istituto Zooprofilattico Sperimentale del Piemonte at Torino)}

Digestion with proteinase K (PK) and Western blotting (WB) using a chemo luminescence imager (ChemiDoc, Biorad) for data collection were followed as described before, except that for AS cases PK was used at 0.02 instead of $0.04 \mathrm{mg} \mathrm{mL}^{-1}$ [43]. Antibodies used were 12B2, 9A2, Sha31 and SAF84 respectively at concentrations $0.2,0.2,0.1$ and $1 \mu \mathrm{g} \operatorname{IgG~mL}{ }^{-1}$.
Triplex-WB procedure (performed at WBVR: Wageningen BioVeterinary Research)

PK was used at $0.05 \mathrm{mg} \mathrm{mL}^{-1}$, and WB performed with a mix of antibodies 12B2, Sha31 and SAF84 on a single membrane at concentrations of respectively $0.2,0.1$ and $0.5 \mu \mathrm{g} \mathrm{mL}^{-1} \mathrm{IgG}$. Calculations on resulting fluorescent antibody signals were carried out with ImageQuant software exactly as before [44]. The fluorescence of the mAbs with respective Zenon labels Alexa647, Alexa488 and Alexa555 (InVitrogen) was normalized to 1 based on recombinant ovPrP $\mathrm{ARQ}$ on each gel. Molecular masses of $\operatorname{PrP}^{\text {res }}$ bands $\mathrm{D}, \mathrm{M}$ and $\mathrm{N}$ (see footnote 2 for triplet band nomenclature) were estimated with Gel-Pro analyser software (Media Cybernetics) using as reference SeeBlue dye markers which are visible at $647 \mathrm{~nm}$. Samples were analysed in triplicate. Parameters calculated from the Image Quant software figures such as molecular masses, 12B2/Sha31 ratios, M/D ratios, D-, M-, and $\mathrm{N}$-fractions, and SAF84/Sha31 ratios at the $24 \mathrm{kDa} \operatorname{PrP}^{\text {res }}$ fraction yielded per sample standard deviations below respectively 4, $2716,5,12,23$ and 17 in percentage of the average.

\section{Raising PK concentration to $1 \mathrm{mg} \mathrm{mL}^{-1}$ for PrPres preparation (ISS-PK)}

To investigate the PK susceptibility of CS cases, a new approach used a high concentration of PK $\left(1 \mathrm{mg} \mathrm{mL}^{-1}\right)$, or in some cases a range of PK concentrations between 0.02 and $4 \mathrm{mg} \mathrm{mL}^{-1} \mathrm{PK}$, followed by ISS-WB. After PK digestion at $1 \mathrm{mg} \mathrm{mL}^{-1}$, the P4/SAF84 ratio was calculated for each sample, relative to the ratio of an internal control (sample I11).

\section{Guanidine-treatment (ISS-Gdn)}

To differentiate CS and CH1641-like isolates from small ruminant BSE a method to test structural stability of the $\operatorname{PrP}^{\mathrm{Sc}}$ core was used [27]. The protocol (ISS-Gdn) included a pre-treatment with $3.5 \mathrm{M}$ guanidine- $\mathrm{HCl}(\mathrm{Gdn})$. Equal aliquots of a sample were either left untreated or treated for $1 \mathrm{~h}$ at $37^{\circ} \mathrm{C}$ and then adjusted to a final concentration of $0.35 \mathrm{M} \mathrm{Gdn}$, and digested with $0.2 \mathrm{mg} \mathrm{mL}^{-1}$ PK. ISS-WB with PrP-core specific mAb SAF84 was used for detection. Stability of $\operatorname{PrP}^{\text {res }}$ core was reflected in the antibody binding signal ratios obtained at 3.5 and $0 \mathrm{M} \mathrm{Gdn}(3.5 \mathrm{M} / 0 \mathrm{M})$.

\section{High pH/PK treatment (WBVR-pH8)}

Another method to test $\operatorname{PrP}^{\text {res }}$ core structural stability consisted of two digestion conditions where one aliquot of sample was digested at $50 \mu \mathrm{g} \mathrm{mL} \mathrm{m}^{-1} \mathrm{PK} / \mathrm{pH} 6.5$ and another aliquot at $500 \mu \mathrm{g} \mathrm{mL}^{-1} \mathrm{PK} / \mathrm{pH} 8$ [26]. WB was performed with $\mathrm{PrP}$ core specific antibody $\mathrm{L} 42$ $\left(0.2 \mu \mathrm{g} \operatorname{IgG~mL} \mathrm{m}^{-1}\right)$ and chemo luminescence detection. 
Antibody signals on films were estimated as before [9]. The relative stability of the $\operatorname{PrP}^{\text {res }}$ core was expressed as the $\mathrm{pH} 8 / \mathrm{pH} 6.5$ signal retention ratio between each set of aliquots.

\section{Statistical analyses}

With statistical software (GraphPad Prism ${ }^{\circledR}$ 8), one-way ANOVA compared three or more unmatched groups, based on the assumption that the populations were Gaussian. When $P$ values were $\leq 0.05$, means were considered to be derived from non-identical populations. In that case, one-way analysis of variance was used to establish whether differences between groups of data were greater $(P \leq 0.05)$ than expected using Bonferroni-Dunn t-test.

\section{Results}

\section{Analyses to discriminate between BSE, classical scrapie and Nor98/atypical scrapie}

Initial analyses were carried out by CEA-ELISA on goat samples from all countries except on those from UK and G11-G17 from Greece. Most fields cases scored as CS with $\mathrm{A}^{\prime} / \mathrm{A}$ ratios $>1.43$, except for sample I3 which showed a borderline BSE value of 1.35 and sample I15 a ratio of 0.05 indicative for AS-like scrapie (Figure 1A). All experimental CS and BSE samples including icgtBSE1 resulted in values as expected for CS and BSE, respectively.

In ISS-WB analysis (see Additional file 3), most field cases fulfilled the two criteria for CS except for samples UK-B2 and I15 (Figures 1B and C). UK-B2 exhibited BSElike features by showing both a low $N$-terminal epitope $\mathrm{PrP}^{\mathrm{res}}$ content $(\mathrm{P} 4 / \mathrm{SAF} 84$ signal ratio $<0.5)$ and $\mathrm{N}$-band $\mathrm{PrP}^{\mathrm{res}}$ molecular mass $>0.5 \mathrm{kDa}$ lower than that of the CS reference I11.

The PrP ${ }^{\text {res }}$ banding pattern of sample I15 was as in AS-like samples with a major band at $8 \mathrm{kDa}$, when using antibody P4, while SAF84 did not show binding (see Additional file 3). This was further confirmed in IZSTOWB with mAbs 12B2, 9A2, Sha31 and SAF84 (data not shown).

Triplex-WB: three-antibody analysis on a single membrane Triplex-WB can yield on one membrane quantifications of molecular properties of PrP ${ }^{\text {res }}$ from the signals of a mix of three mAbs which are in this study 12B2, Sha31 and SAF84 (Figure 2).

Similar results were obtained as above with ISS-WB but now they were estimated relative to the Sha31 signal instead to SAF84. The results can be summarized as follows:
1. in all but one case a high $N$-terminal epitope content with $12 \mathrm{~B} 2 / \mathrm{Sha} 31$ ratios between 0.3 and 1.2 were seen, the exception being UK-B2 (0.1, BSE-like) (Figure 3A); interestingly, the Italian samples as well as F16 and UK-A2 were the lowest in 12B2 epitope content (between 0.3 and 0.9) similar to what was observed with P4 in the ISS-WB (see Additional file 4). The $N$-terminal epitope content of this group of samples was in both WB systems statistically lower than of other CS samples and higher than of the BSE samples $(P<0.001)$.

2. a glycoprofile with $M / D$ ratios $>0.3$ can be observed in all study samples including UK-B2, gtCH1641 and shCH1641 due to a low D fraction in contrast to ratios $\leq 0.2$ in BSE with high D levels. Additionally, the $\mathrm{N}$ band fraction was higher in all CS samples, including $\mathrm{CH} 1641$, than in BSE (Figure 3B).

3. molecular masses of the $\operatorname{PrP}^{\text {res }} \mathrm{N}$-fraction in the CS cases ranging from 19.3 to $21.6 \mathrm{kDa}$, and those of BSE, CH1641 and UK-B2 from 18.7 to $19.4 \mathrm{kDa}$. There was a reasonable linear regression correlation between $N$-terminus epitope content of $(\mathrm{N}+\mathrm{M}+\mathrm{D}$ bands) and the molecular mass of the $\mathrm{N}$ band $\left(R^{2}=0.602\right.$, see Additional file 5$)$.

Banding patterns of Sha31 and SAF84 in UK-B2 were different from CS and BSE samples, but similar to that of control samples C-shCH1641 and C-gtCH1641 in which typically two $\mathrm{PrP}^{\mathrm{res}}$ triplets were present (triplet \#1 bands D1, M1 and N1, triplet \#2 bands D2, M2, and N2 in Figure 2). Of these two triplets, one migrated between 18 and $29 \mathrm{kDa}$ similar to that obtained with

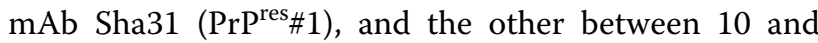
$24 \mathrm{kDa}\left(\mathrm{PrP}^{\mathrm{res}} \mathrm{\#} 2\right)$ only bound by SAF84 (see Additional file 6). Proof for presence of such double triplet composition could be confirmed by using at $24-25 \mathrm{kDa}$ signal of the SAF84 and Sha31 fractions in the 18-29 kDa region (ratio SAF84/Sha31 at $24 \mathrm{kDa}$ ), which in case of CH1641 yields a value around two while single populations are around one. All BSE and CS samples varied around one (range 0.8-1.2) (Figure 3A).

\section{PK sensitivity of PrPres $N$-terminal epitope of CS cases}

The PK-sensitivity of the PrP ${ }^{\text {res }} N$-terminus of CS cases in the two WB methods (see Additional file 4) was further tested by stepwise increasing the PK concentration from 0.02 to $4 \mathrm{mg}$ PK mL $\mathrm{mL}^{-1}$ in several samples comparing the relative binding of P4 and SAF84 epitopes (Figures $4 \mathrm{~A}$ and $\mathrm{B})$. After confirming the reproducibility, all CS samples were subjected to one single PK digestion at $1 \mathrm{mg} \mathrm{mL}^{-1}$ to estimate the P4/SAF84 ratio (ISS-PK method). All Italian samples and F16 were clearly below a ratio cut-off value of 1.4 and considered as a separate 


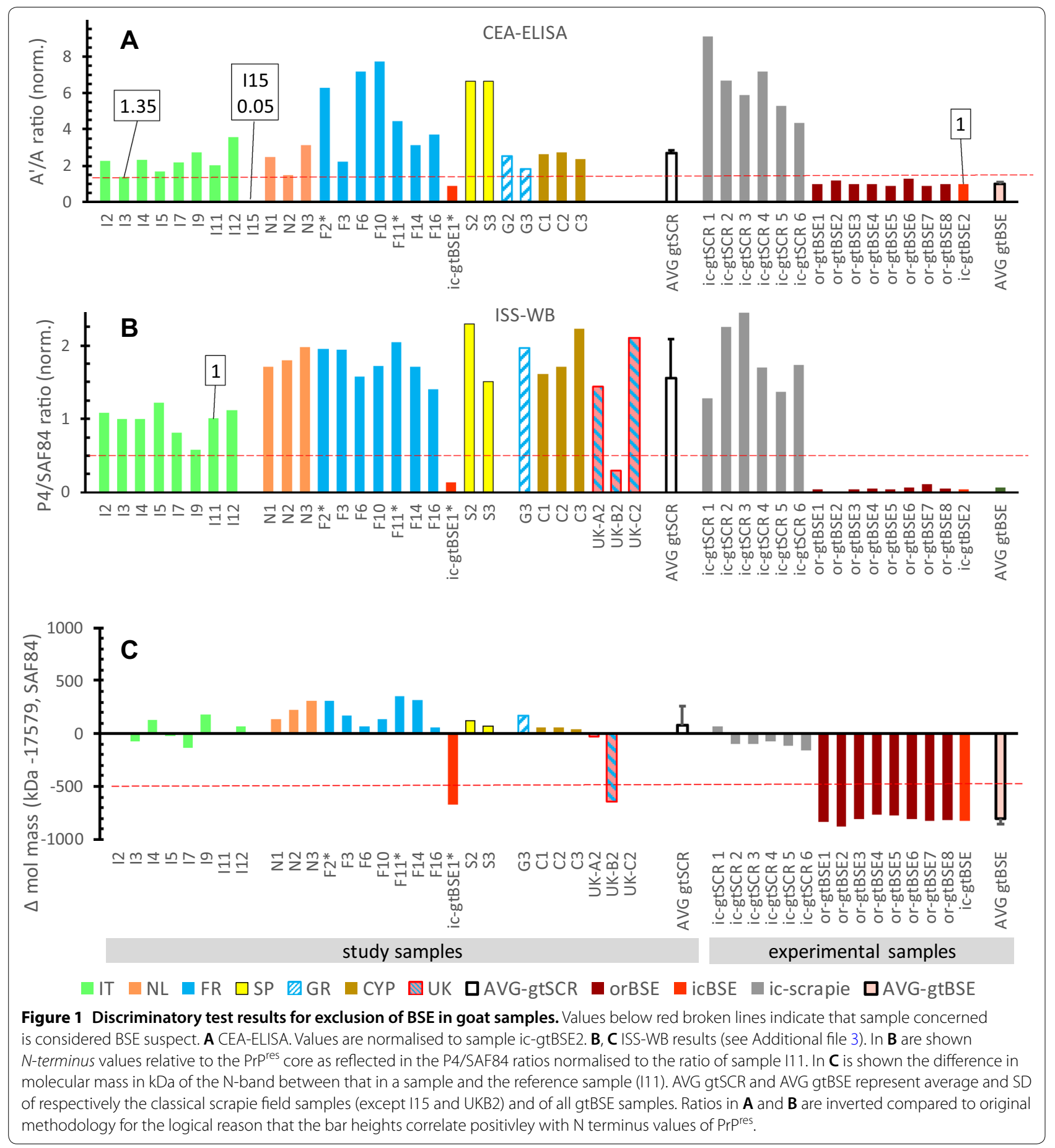

group of CS type. These biochemical groups are here defined for $>1.4$ and $<1.4$ as type CS- 1 and CS-2 respectively (Figure 4C).

\section{Structural stability of total PrPres}

We also investigated the PK resistance of the $\mathrm{PrP}^{\mathrm{res}}$ core region as an indicator of structural stability. This was carried out with two different approaches and WB to probe the effect.

After 3.5 M Gdn- $\mathrm{HCl}$ pre-treatment in the ISS-Gdn method, core epitope loss was probed by ISS-WB to 

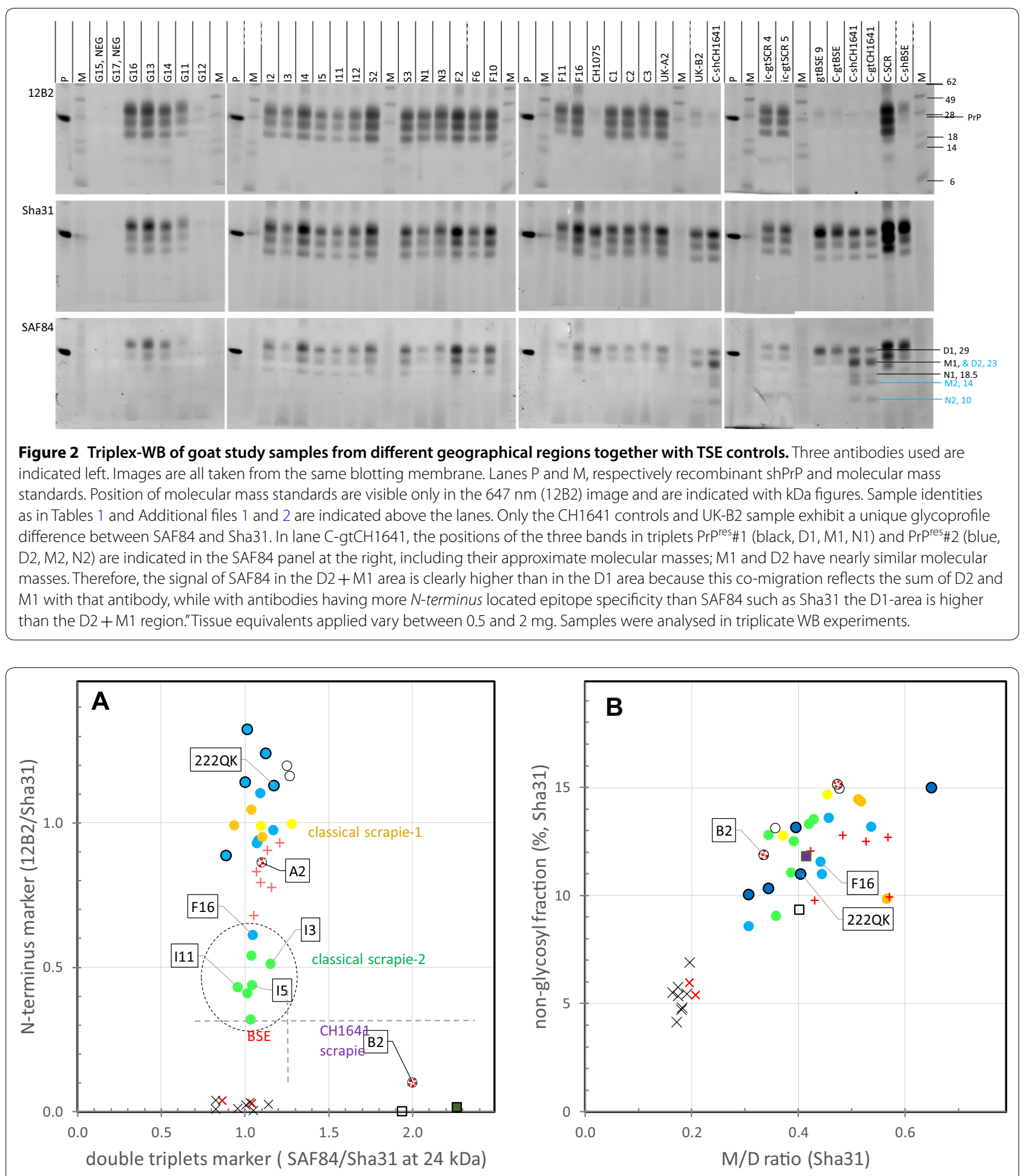

- IT $\bigcirc \mathrm{NL} \bullet \mathrm{FR} \odot \mathrm{SP} O \mathrm{GR} \bullet \mathrm{CY} \otimes \mathrm{UK} \times \mathrm{icBSE} \times$ orBSE + icSCR $\square \mathrm{shCH} 1641 \square \mathrm{gtCH} 1641$

Figure 3 Dot plots of data obtained from Triplex-WB of PrPres as in Figure 2. Each dot represents an individual goat TSE sample analysed in triplicate. Symbols: circles represent field cases and colour the country of origin; other symbols represent experimental samples and control samples from sheep or goat. A Plot with marker for N terminus epitope level on vertical axis versus PrPres double triplets marker on horizontal axis. Horizontal and vertical broken lines indicate the clear separation between CS, CH1641 and BSE. The lower N-terminus marker values of Italian cases and F16 are striking (encircled). B Triplet glycoprofile markers with non-glycosylated (N) fraction on vertical axis and on horizontal axis the ratio between signals in mono-glycosylated (M) and di-glycosylated fraction (D). A difference is obvious between BSE cases (low N and low M/D, due to high D levels in BSE samples) with CS and CH1641 cases. 


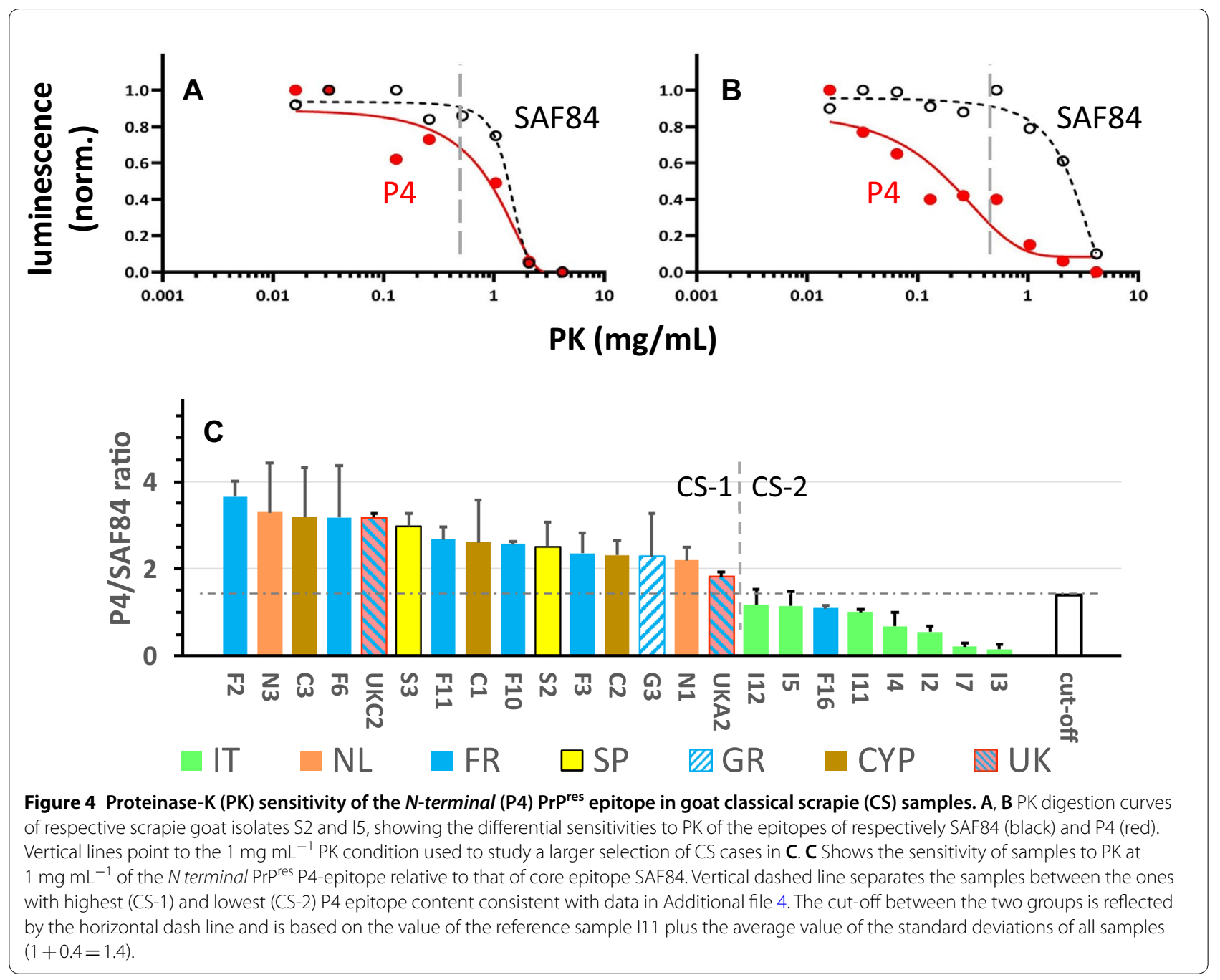

measure the SAF84 signals at $3.5 \mathrm{M}$ relative to that without pre-treatment. All CS study cases and CH1641 specimens were quite sensitive for PK digestion with $3.5 \mathrm{M} / 0 \mathrm{M}$ ratios lower than 0.35 (i.e. $>65 \%$ core epitope loss) including UK-B2 (89\% loss), while BSE samples were significantly more resistant with less than $45 \%$ loss (Figure 5A).

The WBVR-pH8 method compared high and normal pH during PK digestion. Expressed by the L42 signal ratio $\mathrm{pH} 8 / \mathrm{pH} 6.5$, this yielded low and high retention ratios for CS and BSE, respectively (Figure 5B). While the CS cases on average lost around $62 \%($ ratio $<0.38)$ of antibody binding, the goat BSE sample showed the lowest loss of binding up to only $36 \%$ (ratio $>0.64$ ). A reference sample of sheep scrapie showed higher signal loss than sheep BSE-56\% compared to $15 \%$-in line with what had already been observed before [26].

\section{Discussion}

The combined efforts in different laboratories, which shared the same goat brain macerates, enabled a thorough investigation using various chemical pre-treatments and subsequent biochemical analyses to clearly establish that none of the field cases was BSE.

On the other hand, the combined biochemical evidence from over 30 different field cases of prion disease collected from seven different European countries shows clearly that in goats similar types of scrapie occur as in sheep, which are atypical/Nor98 (AS) scrapie and several forms of classical scrapie (CS). Potentially three types of CS could be discriminated differing in increasing order of protease sensitivity of the $\mathrm{N}$-terminus of $\mathrm{PrP}^{\mathrm{Sc}}$ : CS-1 occurring most frequently, CS-2 occurring-but probably not only-in Italy, and one unambiguous CH1641like case found in a scrapie infected herd in the United Kingdom (see column Molecular TSE-type, Table 1). 


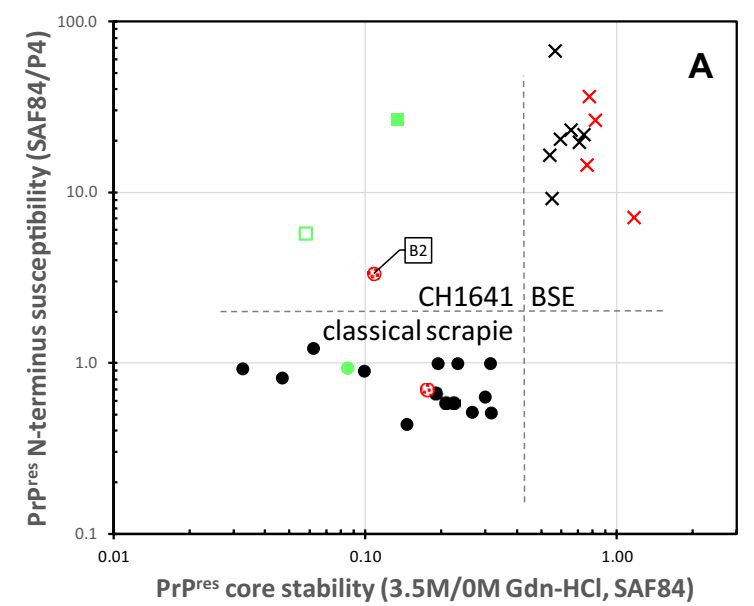

- IT-NL-FR-SP OUK XicBSE X orBSE @ shSCR $\square$ ic-shCH1641-b $\square$ shCH1641-like

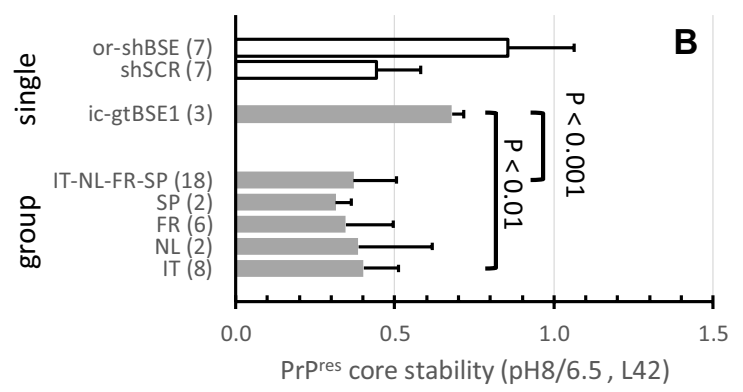

Figure 5 Stability of PrPres core region after denaturing and basic pretreatment of goat study samples. A The effect of $3.5 \mathrm{M}$ $\mathrm{Gdn}-\mathrm{HCl}$ treatment on susceptibility to proteolytic degradation was compared to normal condition when analysed by ISS-WB with mAb SAF84. The denaturation yielded high core epitope losses in the CS and $\mathrm{CH} 1641$ samples, but not in BSE samples where the PrPres core apparently is highly stable (horizontal axis). The vertical axis shows the susceptibility of the PrPres $\mathrm{N}$-terminus under normal conditions of the ISS-WB process. B The effect of basic $\mathrm{pH} 8$ pre-treatment on subsequent proteolytic degradation. Only samples from four countries were tested. The BSE samples appeared the most resistant against proteolytic degradation of the Prpres core. All field samples from Italy, Netherlands, France and Spain together and separately from each country did exhibit a significantly higher susceptibility to Gdn denaturation than goatBSE, as indicated with the $P$ values (Bonferroni-Dunn method).

\section{Biochemical parameters for typing TSEs}

In this study, nine different molecular PrPres parameters appeared useful to discriminate TSE types in brain homogenates of native goat samples (Table 2). These were glycoprofile $(\mathrm{M} / \mathrm{D}$ and $\% \mathrm{~N})$, PK resistance of the $N$-terminus (three approaches), molecular mass of $\operatorname{PrP}^{\text {res }}$ bands (reflected in the non-glycosylated fraction), double triplet composition, core sequence stability and-for AS-absence of a C-terminal fragment covering roughly the 154-234 PrP sequence corroborating a previous study [45].

One of these parameters is a new candidate and dependent on a $1 \mathrm{mg} \mathrm{mL}^{-1} \mathrm{PK}$ treatment that effectively leads to differentiation between the CS subclasses CS-1 and CS-2. While in the three tests using Western blotting (ISS-WB, Triplex-WB and ISS-P with high PK concentrations) the difference in $\mathrm{PK}$ susceptibility of the PrP $\mathrm{P}^{\text {res }}$ $N$-terminal domain was obvious this was not the case in the ELISA. The explanation could well be that the ELISA is dependent on the presence of a more $N$-terminally located epitope between PrP amino acid residues 70-76 used in the ELISA compared to the P4 and 12B2 epitopes in these three WB tests which epitopes are located more down stream the PrP-sequence i.e. between residues 93-97. The ELISA is therefore more sensitive for removal of N-terminal amino acids at sites in the 70-93 amino acid region of PrP, which might be helpful in finding the deviant cases but not to recognize truly BSE-like cases.

For differentiating CS-CH1641 from BSE several robust parameters were available which are the two glycoprofile markers $M / D$ ratio and percentage of the $\mathrm{N}$-fraction, structural stability and the unique presence of two PrP ${ }^{\text {res }}$ triplets.

\section{Are biochemically distinct classical scrapie types related to different strains?}

The different $\mathrm{PrP}^{\mathrm{res}}$ signatures of the CS-1, CS-2 and CS-CH1641 cases might have at least two different origins. One would be that it is a host dependent phenomenon in which a common scrapie strain in certain hosts shows up with a PrPres triplet property as observed under the current biochemical treatments for diagnosis. In this case, the host is determining the biochemical phenotype of the strain by yet unknown factors. The other possibility could be that the phenomenon is a real strain property, which in the particular in case of CS-CH1641 is even rarely observed in sheep and goats. If so, it should be possible to make scrapie strain types visible in transgenic mice with various ovine (or caprine) PRNP expression levels [46]. Also, the effect of PrP polymorphisms need to be considered. To figure this out quite a number of rodent models are nowadays available to enable such typing studies.

\section{Significance of TSE-type for resistance breeding and polymorphisms}

As with sheep, rapid typing of potential TSE agents in goats is necessary since different types can have different genetic susceptibilities $[47,48]$ or even different zoonotic potential [49]. Resistance/susceptibility to TSEs in mammals including the human species is dependent on genetic variation in the PRNP gene coding sequence 
Table 2 PrP ${ }^{\text {res }}$ parameters that differentiate TSE-types in goats

\begin{tabular}{|c|c|c|c|c|c|}
\hline PrPres parameter & CS-1 & CS-2 & CS-CH1641 & BSE & AS \\
\hline \multicolumn{6}{|l|}{ Glycoprofile $e^{a}$} \\
\hline M\%/D\% ratio, Sha31 & High (>0.3) & High (>0.3) & High $(>0.3)$ & $\operatorname{Low}(<0.2)$ & NA \\
\hline N\%, Sha31 & High (> 8\%) & High (> 8\%) & High (> 8\%) & Low $(<8 \%)$ & NA \\
\hline \multicolumn{6}{|l|}{$\mathrm{N}$-terminus level ${ }^{\mathrm{b}}$} \\
\hline Normal PK: 12B2/Sha31 ratio & High (0.8-1.3) & Interm. (0.3-0.7) & Low $(<0.2)$ & $\operatorname{Low}(<0.2)$ & NA \\
\hline High PK: P4/SAF84 ratio & High (1.4-4) & Interm. (0.2-1.3) & ND & ND & NA \\
\hline High PK: A'/A ratio, SAF34 + Bar224 & High $(>0.3)$ & High (>0.3) & ND & Low $(0.8-1.3)$ & minute $(\ll 0.8)$ \\
\hline \multicolumn{6}{|l|}{$\mathrm{kDa}(\mathrm{N}-\mathrm{band})^{\mathrm{c}}$} \\
\hline Triplex-WB, Sha31 & $19.9-21.6$ & $19.3-20.6$ & $18.5-19.5^{\mathrm{e}}$ & $18.5-19.5$ & NA \\
\hline ISS-WB, SAF84 & 17.5 & 17.5 & $16-17$ & $16-17$ & 8 \\
\hline Triplet profile, SAF84/Sha31 ratio at 22-24 kDa & Single & Single & Double & Single & Absent \\
\hline Core stability: SAF84 and L42 & Low & Low & Low & High & NA \\
\hline PrP C-terminus $\sim 154-234^{d}$ & Present & Present & Present & Present & Absent \\
\hline
\end{tabular}

Nine parameters of PrPS obtained after differential PK digestion of TSE infected goat brain and WB. Epitope location determines the outcome. The italic texts indicate differences between CS-1 and CS-2. Between parentheses are the ranges in quantitative values as obtained in Triplex-WB (Sha31 related), ISS-WB (SAF84 related) or ELISA (SAF34 + Bar224 related). The ranges are relative to the different categories, not absolute, and should be compared per experiment with proper controls (BSE, CS-1, CS-2, CS-CH1641). ND: analysis not done, NA: not applicable due to absence of a classical PrPres triplet. These typing tests may well work also on sheep TSE samples

a Glycoprofile estimated by ISS-WB with SAF84 did show similar discriminatory properties as with Sha31 for C-1, CS-2, and CH1641 M/D values $>0.4$ and BSE $<0.4$, and N percentages for $\mathrm{CS}>13 \%$ and $\mathrm{BSE}<13 \%$

b Result with 12B2/Sha31 from Triplex-WB, P4/SAF84 from ISS-WB and SAF34 + Bar224 from CEA ELISA

c These two rows represent the same differentiating parameter. Differences between ISS-WB and Triplex-WB in molecular mass values are due to use of different gel systems and molecular mass standards

d Absence of PrP region 154-234 is based on presence of Sha31 epitope and absence of SAF84 epitope corroborating interpretations by Pirisinu et al. [45]

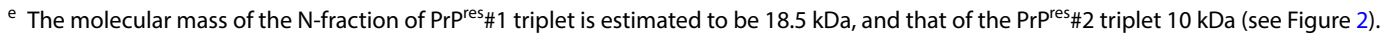

[50-53]. In goats this polymorphism variability is partly similar to that in sheep and currently at least 51 coding polymorphisms have been described in goat [54]. In our set of field cases goats with several PRNP genotypes were selected (Table 1), including two scrapie positive goats (G11 and G12) carrying a scrapie resistance related lysine at codon 222 in heterozygosity both of which contained very low $\operatorname{PrP}^{\text {res }}$ levels (see Additional file 2). However, there appeared to be no association between the variability in biochemical characteristics of $\operatorname{PrP}^{\text {res }}$ and PRNP genotype in this study. Breed of animals could be another reason for phenotypical variability but although the breed of most animals was known it is not possible to connect this information to our results by lack of sufficient samples and because within the breed itself $\operatorname{PrP}$ polymorphism distribution can greatly differ $[55,56]$.

\section{Geographical differences}

Little is actually known about geographical differences with respect to the occurrence of prion strains. In this study on goats from seven European countries-Italy, France, Greece, Cyprus, Spain, Netherlands and United
Kingdom-material was collected and distributed to participating partners from single macerates. From our stability experiments, PK treatments and the two different antibody combinations (P4/SAF84 and 12B2/ Sha31/SAF84) used in the WB analyses, CS-2 is an example of geographic variation of scrapie types. This form does occur mainly both in mainland Italy and Sicily, and possibly also sometimes in other countries such as France (example F16). Whether this CS-2 type has a source in Italy in the use of a vaccine against $\mathrm{Myco}$ plasma agalactiae in both goats and sheep during the late 1990s is a possibility [57]. CS-1 might have existed before in Italy, but maybe the vaccination strain has become the dominant one.

\section{Prospects}

Similarities between sheep and goats in genetics and the prion protein sequence itself were also encountered in the TSE types discerned in this study on goat scrapie field cases. Our consortium will report separately whether these biochemical typing studies in the macerates are linked to any strain type after first passage in an unprecedented broad set of rodent models. So far 
it seems, that the CS-2 cases also in the rodent models point to a separate strain that underscores the importance of further developing biochemical tools for TSE type discrimination [58].

\section{Supplementary information}

Supplementary information accompanies this paper at https://doi. org/10.1186/s13567-019-0718-z.

Additional file 1. Experimentally generated goat scrapie and BSE isolates, and some control samples used in this study. Table containing details of the reference and control samples used in the study.

Additional file 2. Overview of the application of seven different biochemical analyses in goat and control samples. Table containing goat sample sets used in the specific type of analyses performed.

Additional file 3. ISS-WB of goat TSE brain samples from different geographical regions with antibodies P4 and SAF84. Figure of ISS-WB with mAbs P4 and SAF84 on the set of goat study samples.

Additional file 4. Sample ranking to their relative levels of $\mathbf{N}$-terminal PrP $^{\text {res }}$ epitopes of antibodies P4 and 12B2. Figure in histogram form to compare the ranking of goat study sample series from high to low $N$-terminal epitope in ISS-WB and Triplex-WB.

Additional file 5 . Correlation between $\mathbf{N}$-terminus data and molecular mass of the PrP ${ }^{\text {res }}$ non-glycosylated band obtained by Triplex-WB. Figure in dotplot form showing the correspondence between total PrPres $N$-terminus level and molecular mass of non-glycosylated PrPres fraction.

Additional file 6. Graphic comparison of the PrPres double and single triplet state in resp. CH1641 and scrapie/BSE. Figure showing difference in migration of PrPres bands in CH1641 scrapie samples, goat study sample UK-B2 and reference TSEs as obtained with mAbs Sha31 and SAF84 in Triplex-WB.

\section{Acknowledgements}

We want to pay our respect for the very skilled contributions of both WBVR engineers Jo Erkens and Jorg Jacobs who did pass away, JE in 2015 and JGJ in 2017. We thank Dr. Gabriele Vaccari (ISS, Rome) for his advises in our goat research, Dr. Human Rezeai (INRA, Jouy-en Josas) for providing rec-ovinePrP, and Dr. Thierry Baron (ANSES, Lyon) for supplying a sheep CH1641 field sample.

\section{Authors' contributions}

PLA, CA, LE, TS, LJMvK, AB, IL, JS, WG, PP-S, MG, CF, FL, and OA did collected goat samples; UA and RN did manage data collection for the goat samples; $\mathrm{IL}$ and FL prepared brain macerates; IL and JPML took care for distribution of macerates; SS performed ELISAs; LP and EE did carry out ISS-WB and additional pretreatments in ISS-Gdn and ISS-PK; JGJ and JPML performed Triplex-WB and WBVR-pH8 pretreatments; MM and PLA performed the IZSTO-WB work; JPML wrote the manuscript; RN, LP, WG, MG, CF, PLA, MM and LJMvK did significantly assist in the writing; $A B$ was overall project leader. All authors read and approved the final manuscript.

\section{Funding}

This work was supported by the European Commission: NeuroPrion [EC FOOD-CT-2004-506579], GoatBSE [EC FOOD-CT-2006-36353], GOAT-TSE-FREE [ERA-NET EMIDA] and by National fundings: Netherlands-Ministry of Agriculture, Nature and Food Quality [WOT 01-002-001.01]; Italy_Italian Ministry of Health [RF-2009-1474624]; Spain-Ministry of Economy and Competitiveness [AGL2012-40071]; United Kingdom-Department for Environment, Food and Rural Affairs [SE2018] [SE1961], Biotechnology and Biological Sciences Research Council [BB/J004332/1]; Greece-Greek Ministry of Education; and France - Institut National de la Recherche Agronomique TRANSPRION [EFA282/13], REDPRION [EFA148/16]. Parts of this study were presented this year at the international conference on prion diseases "Prion 2019" in Edmonton, Canada by Dr Romolo Nonno and Dr Laura Pirisinu in oral and poster presentation.

\section{Ethics approval and consent to participate}

A few controls samples have been separately produced in the laboratory of WBVR in sheep and goat. To obtain these materials the experiments were performed according to European directive 2010/63/EU as well as in agreement with the Dutch Central Authority for 519 Scientific Procedures on Animals, permit number AVD401002016522.

\section{Competing interests}

The authors declare that they have no competing interests.

\section{Author details}

${ }^{1}$ Wageningen BioVeterinary Research (WBVR), Wageningen University \& Research, Houtribweg 39, 8221RA Lelystad, The Netherlands. ${ }^{2}$ Department of Veterinary Public Health and Food Safety, Istituto Superiore di Sanita (ISS), 299-00161 Rome, Italy. ${ }^{3}$ Italian Reference Centre for TSEs, Istituto Zooprofilattico Sperimentale del Piemonte (IZSTO), 10154 Turin, TO, Italy. ${ }^{4}$ UMR 1282 ISP, Institut National de la Recherche Agronomique (INRA), University of Tours, 37380 Nouzilly, France. ${ }^{5}$ Commissariat à l'Énergie Atomique (CEA), 91191 Gif-sur-Yvette, France. ${ }^{6}$ UMR INRA/ENVT 1225 IHAP, École Nationale Vétérinaire de Toulouse (ENVT), 31300 Toulouse, France. ${ }^{7}$ Research Centre for TSE and Emerging Transmissible Diseases, University of Zaragoza (UNIZAR), 50013 Zaragoza, Spain. ${ }^{8}$ Friedrich-Loeffler-Institut (FLI), Institute of Novel and Emerging Infectious Diseases, Greifswald-Isle of Riems, 17493 Greifswald, Germany. ${ }^{9}$ The Roslin Institute and Royal (Dick) School of Veterinary Studies, University of Edinburgh (UEDIN), Easter Bush, Midlothian EH25 9RG, UK.

${ }^{10}$ Department of Pathology, Animal and Plant Health Agency (APHA), Woodham Lane, Addlestone, Surrey KT15 3NB, UK. ${ }^{11}$ School of Pharmacy, Aristotle University of Thessaloniki (AUTh), 54124 Thessaloniki, Greece. ${ }^{12}$ Hellenic Agricultural Organization DEMETER, Veterinary Research Institute, 57001 Thessaloniki, Greece. ${ }^{13}$ Veterinary Services (VSC), Ministry of Agriculture, Rural Development and Environment, 1417 Nicosia, Cyprus.

Received: 23 July 2019 Accepted: 16 October 2019

Published online: 25 November 2019

\section{References}

1. Collinge J, Clarke AR (2007) A general model of prion strains and their pathogenicity. Science 318:930-936

2. Prusiner SB (1982) Novel proteinaceous infectious particles cause scrapie. Science 216:136-144

3. Wells GA, Scott AC, Johnson CT, Gunning RF, Hancock RD, Jeffrey M, Dawson M, Bradley R (1987) A novel progressive spongiform encephalopathy in cattle. Vet Rec 121:419-420

4. Wilesmith JW, Wells GA, Cranwell MP, Ryan JB (1988) Bovine spongiform encephalopathy: epidemiological studies. Vet Rec 123:638-644

5. Bruce ME, Will RG, Ironside JW, McConnell I, Drummond D, Suttie A, McCardle L, Chree A, Hope J, Birkett C, Cousens S, Fraser H, Bostock CJ (1997) Transmissions to mice indicate that 'new variant' $C J D$ is caused by the BSE agent. Nature 389:498-501

6. Will RG, Ironside JW, Zeidler M, Cousens SN, Estibeiro K, Alperovitch A, Poser S, Pocchiari M, Hofman A, Smith PG (1996) A new variant of Creutzfeldt-Jakob disease in the UK. Lancet 347:921-925

7. Biacabe AG, Laplanche JL, Ryder S, Baron T (2004) Distinct molecular phenotypes in bovine prion diseases. EMBO Rep 5:110-115

8. Casalone C, Zanusso G, Acutis P, Ferrari S, Capucci L, Tagliavini F, Monaco S, Caramelli M (2004) Identification of a second bovine amyloidotic spongiform encephalopathy: molecular similarities with sporadic Creutzfeldt-Jakob disease. Proc Natl Acad Sci USA 101:3065-3070

9. Jacobs JG, Langeveld JP, Biacabe AG, Acutis PL, Polak MP, Gavier-Widen D, Buschmann A, Caramelli M, Casalone C, Mazza M, Groschup M, Erkens JH, Davidse A, van Zijderveld FG, Baron T (2007) Molecular discrimination of atypical bovine spongiform encephalopathy strains from a geographical region spanning a wide area in Europe. J Clin Microbiol 45:1821-1829

10. Houston F, Andréoletti $O$ (2019) Animal prion diseases: the risks to human health. Brain Pathol 29:248-262

11. Babelhadj B, Di Bari MA, Pirisinu L, Chiappini B, Gaouar SBS, Riccardi G, Marcon S, Agrimi U, Nonno R, Vaccari G (2018) Prion disease in dromedary camels, Algeria. Emerg Infect Dis 24:1029-1036 
12. Benestad SL, Mitchell G, Simmons M, Ytrehus B, Vikoren T (2016) First case of chronic wasting disease in Europe in a Norwegian free-ranging reindeer. Vet Res 47:88

13. Williams ES, Young S (1980) Chronic wasting disease of captive mule deer: a spongiform encephalopathy. J Wildl Dis 16:89-98

14. Deleault NR, Piro JR, Walsh DJ, Wang F, Ma J, Geoghegan JC, Supattapone S (2012) Isolation of phosphatidylethanolamine as a solitary cofactor for prion formation in the absence of nucleic acids. Proc Natl Acad Sci USA 109:8546-8551

15. Bruce ME, Dickinson AG (1987) Biological evidence that scrapie agent has an independent genome. J Gen Virol 68:79-89

16. Aguilar-Calvo P, Espinosa JC, Andreoletti O, Gonzalez L, Orge L, Juste R, Torres JM (2016) Goat K222-PrP(C) polymorphic variant does not provide resistance to atypical scrapie in transgenic mice. Vet Res 47:96

17. Vaccari G, Panagiotidis CH, Acin C, Peletto S, Barillet F, Acutis P, Bossers A, Langeveld J, van Keulen L, Sklaviadis T, Badiola JJ, Andréoletti O, Groschup MH, Agrimi U, Foster J, Goldmann W (2009) State-of-the-art review of goat TSE in the European Union, with special emphasis on PRNP genetics and epidemiology. Vet Res 40:48

18. Zlotnik I, Rennie JC (1963) Further observations on the experimental transmission of scrapie from sheep and goats to laboratory mice. J Comp Pathol 73:150-162

19. Eloit M, Adjou K, Coulpier M, Fontaine JJ, Hamel R, Lilin T, Messiaen S, Andreoletti O, Baron T, Bencsik A, Biacabe AG, Beringue V, Laude H, Le Dur A, Vilotte JL, Comoy E, Deslys JP, Grassi J, Simon S, Lantier F, Sarradin P (2005) BSE agent signatures in a goat. Vet Rec 156:523-524

20. Jeffrey M, Martin S, Gonzalez L, Foster J, Langeveld JP, van Zijderveld FG, Grassi J, Hunter N (2006) Immunohistochemical features of PrP(d) accumulation in natural and experimental goat transmissible spongiform encephalopathies. J Comp Pathol 134:171-181

21. Spiropoulos J, Lockey R, Sallis RE, Terry LA, Thorne L, Holder TM, Beck KE, Simmons MM (2011) Isolation of prion with BSE properties from farmed goat. Emerg Infect Dis 17:2253-2261

22. Baron TG, Madec JY, Calavas D, Richard Y, Barillet F (2000) Comparison of French natural scrapie isolates with bovine spongiform encephalopathy and experimental scrapie infected sheep. Neurosci Lett 284:175-178

23. Benestad SL, Sarradin P, Thu B, Schonheit J, Tranulis MA, Bratberg B (2003) Cases of scrapie with unusual features in Norway and designation of a new type, Nor98. Vet Rec 153:202-208

24. Gielbert A, Thorne JK, Hope J (2015) Pyroglutamyl-N-terminal prion protein fragments in sheep brain following the development of transmissible spongiform encephalopathies. Front Mol Biosci 2:7

25. Hill AF, Sidle KC, Joiner S, Keyes P, Martin TC, Dawson M, Collinge J (1998) Molecular screening of sheep for bovine spongiform encephalopathy. Neurosci Lett 255:159-162

26. Langeveld JP, Jacobs JG, Erkens JH, Baron T, Andreoletti O, Yokoyama T, van Keulen LJ, van Zijderveld FG, Davidse A, Hope J, Tang Y, Bossers A (2014) Sheep prions with molecular properties intermediate between classical scrapie, BSE and CH1641-scrapie. Prion 8:296-305

27. Pirisinu L, Migliore S, Di Bari MA, Esposito E, Baron T, D’Agostino C, De Grossi L, Vaccari G, Agrimi U, Nonno R (2011) Molecular discrimination of sheep bovine spongiform encephalopathy from scrapie. Emerg Infect Dis 17:695-698

28. Simon S, Nugier J, Morel N, Boutal H, Creminon C, Benestad SL, Andreoletti O, Lantier F, Bilheude JM, Feyssaguet M, Biacabe AG, Baron T, Grassi J (2008) Rapid typing of transmissible spongiform encephalopathy strains with differential ELISA. Emerg Infect Dis 14:608-616

29. Tang Y, Gielbert A, Jacobs JG, Baron T, Andreoletti O, Yokoyama T, Langeveld JP, Sauer MJ (2012) All major prion types recognised by a multiplex immunofluorometric assay for disease screening and confirmation in sheep. J Immunol Methods 380:30-39

30. Vulin J, Biacabe AG, Cazeau G, Calavas D, Baron T (2011) Molecular typing of protease-resistant prion protein in transmissible spongiform encephalopathies of small ruminants, France, 2002-2009. Emerg Infect Dis 17:55-63

31. Stack M, Jeffrey M, Gubbins S, Grimmer S, Gonzalez L, Martin S, Chaplin M, Webb P, Simmons M, Spencer Y, Bellerby P, Hope J, Wilesmith J, Matthews $D$ (2006) Monitoring for bovine spongiform encephalopathy in sheep in Great Britain, 1998-2004. J Gen Virol 87:2099-2107

32. Simmons MM, Chaplin MJ, Vickery CM, Simon S, Davis L, Denyer M, Lockey R, Stack MJ, O'Connor MJ, Bishop K, Gough KC, Maddison BC,
Thorne L, Spiropoulos J (2015) Does the presence of scrapie affect the ability of current statutory discriminatory tests to detect the presence of bovine spongiform encephalopathy? J Clin Microbiol 53:2593-2604

33. Goldmann W, Hunter N, Foster JD, Salbaum JM, Beyreuther K, Hope J (1990) Two alleles of a neural protein gene linked to scrapie in sheep. Proc Natl Acad Sci USA 87:2476-2480

34. Feraudet $C$, Morel N, Simon S, Volland H, Frobert $Y$, Creminon C, Vilette D, Lehmann S, Grassi J (2005) Screening of 145 anti-PrP monoclonal antibodies for their capacity to inhibit PrPSc replication in infected cells. J Biol Chem 280:11247-11258

35. Jacobs JG, Bossers A, Rezaei H, van Keulen LJ, McCutcheon S, Sklaviadis T, Lantier I, Berthon P, Lantier F, van Zijderveld FG, Langeveld JP (2011) Proteinase K-resistant material in ARR/VRQ sheep brain affected with classical scrapie is composed mainly of VRQ prion protein. J Virol 85:12537-12546

36. Langeveld JP, Jacobs JG, Erkens JH, Bossers A, van Zijderveld FG, van Keulen $\sqcup J$ (2006) Rapid and discriminatory diagnosis of scrapie and BSE in retro-pharyngeal lymph nodes of sheep. BMC Vet Res 2:19

37. Morel N, Simon S, Frobert Y, Volland H, Mourton-Gilles C, Negro A, Sorgato MC, Creminon C, Grassi J (2004) Selective and efficient immunoprecipitation of the disease-associated form of the prion protein can be mediated by nonspecific interactions between monoclonal antibodies and scrapieassociated fibrils. J Biol Chem 279:30143-30149

38. Slootstra JW, Puijk WC, Ligtvoet GJ, Langeveld JP, Meloen RH (1996) Structural aspects of antibody-antigen interaction revealed through small random peptide libraries. Mol Divers 1:87-96

39. Fast C, Goldmann W, Berthon P, Tauscher K, Andreoletti O, Lantier I, Rossignol C, Bossers A, Jacobs JG, Hunter N, Groschup MH, Lantier F, Langeveld JPM (2017) Protecting effect of PrP codons M142 and K222 in goats orally challenged with bovine spongiform encephalopathy prions. Vet Res 48:52

40. Lacroux C, Perrin-Chauvineau C, Corbiere F, Aron N, Aguilar-Calvo P, Torres JM, Costes P, Bremaud I, Lugan S, Schelcher F, Barillet F, Andreoletti O (2014) Genetic resistance to scrapie infection in experimentally challenged goats. J Virol 88:2406-2413

41. EU-TSE-Reference-Laboratory (2018) TSE strain characterisation in small ruminants. https://science.vla.gov.uk/tse-lab-net/documents/tse-oie-rlhandbook.pdf. Accessed 18 July 2019

42. Migliore S, Esposito E, Pirisinu L, Marcon S, Di Bari M, D’Agostino C, Chiappini B, Conte M, Sezzi E, De Grossi L, Agrimi U, Vaccari G, Nonno R (2012) Effect of PrP genotype and route of inoculation on the ability of discriminatory Western blot to distinguish scrapie from sheep bovine spongiform encephalopathy. J Gen Virol 93:450-455

43. Mazza M, Iulini B, Vaccari G, Acutis P, Martucci F, Esposito E, Peletto S, Barocci S, Chiappini B, Corona C, Barbieri I, Caramelli M, Agrimi U, Casalone C, Nonno R (2010) Co-existence of classical scrapie and Nor98 in a sheep from an Italian outbreak. Res Vet Sci 88:478-485

44. van Keulen LJ, Langeveld JP, Dolstra CH, Jacobs J, Bossers A, van Zijderveld FG (2015) TSE strain differentiation in mice by immunohistochemical $\operatorname{PrP}(\mathrm{Sc})$ profiles and triplex Western blot. Neuropathol Appl Neurobiol 41:756-779

45. Pirisinu L, Nonno R, Esposito E, Benestad SL, Gambetti P, Agrimi U, Zou WQ (2013) Small ruminant nor98 prions share biochemical features with human Gerstmann-Straussler-Scheinker disease and variably proteasesensitive prionopathy. PLoS One 8:e66405

46. Le Dur A, Laï TL, Stinnakre MG, Laisné A, Chenais N, Rakotobe S, Passet B, Reine F, Soulier S, Herzog L, Tilly G, Rézaei H, Béringue V, Vilotte JL, Laude H (2017) Divergent prion strain evolution driven by PrPC expression level in transgenic mice. Nat Commun 8(14170):1-11

47. Gonzalez L, Jeffrey M, Dagleish MP, Goldmann W, Siso S, Eaton SL, Martin S, Finlayson J, Stewart P, Steele P, Pang Y, Hamilton S, Reid HW, Chianini F (2012) Susceptibility to scrapie and disease phenotype in sheep: crossPRNP genotype experimental transmissions with natural sources. Vet Res 43:55

48. Houston F, Goldmann W, Foster J, Gonzalez L, Jeffrey M, Hunter N (2015) Comparative susceptibility of sheep of different origins, breeds and PRNP genotypes to challenge with bovine spongiform encephalopathy and scrapie. PLoS One 10:e0143251

49. Cassard H, Torres JM, Lacroux C, Douet JY, Benestad SL, Lantier F, Lugan S, Lantier I, Costes P, Aron N, Reine F, Herzog L, Espinosa JC, Beringue V, 
Andreoletti O (2014) Evidence for zoonotic potential of ovine scrapie prions. Nat Commun 5:5821

50. Acutis PL, Bossers A, Priem J, Riina MV, Peletto S, Mazza M, Casalone C, Forloni G, Ru G, Caramelli M (2006) Identification of prion protein gene polymorphisms in goats from Italian scrapie outbreaks. J Gen Virol 87:1029-1033

51. Belt PB, Muileman IH, Schreuder BE, Bos-de Ruijter J, Gielkens AL, Smits MA (1995) Identification of five allelic variants of the sheep PrP gene and their association with natural scrapie. J Gen Virol 76:509-517

52. Mead S, Whitfield J, Poulter M, Shah P, Uphill J, Campbell T, Al-Dujaily H, Hummerich H, Beck J, Mein CA, Verzilli C, Whittaker J, Alpers MP, Collinge J (2009) A novel protective prion protein variant that colocalizes with kuru exposure. N Engl J Med 361:2056-2065

53. Papasavva-Stylianou P, Kleanthous M, Toumazos P, Mavrikiou P, Loucaides P (2007) Novel polymorphisms at codons 146 and 151 in the prion protein gene of Cyprus goats, and their association with natural scrapie. Vet J 173:459-462

54. Goldmann W (2018) Classic and atypical scrapie—a genetic perspective In: Pocchiari M, Manson J (eds) Human prion diseases, vol 153. Elsevier B.V, Amsterdam, pp 111-120
55. Ricci A, Panel E, Snary E (2017) Genetic resistance to transmissible spongiform encephalopathies (TSE) in goats. EFSA J 15:4962

56. Windig JJ, Hoving RA, Priem J, Bossers A, van Keulen LJ, Langeveld JP (2016) Variation in the prion protein sequence in Dutch goat breeds. J Anim Breed Genet 133:366-374

57. Agrimi U, Ru G, Cardone F, Pocchiari M, Caramelli M (1999) Epidemic of transmissible spongiform encephalopathy in sheep and goats in Italy. Lancet 353:560-561

58. Nonno R, Marin-Moreno A, Espinosa JC, Fast C, Van Keulen L, Spiropoulos J, Lantier I, Andreoletti O, Pirisinu L, Di Bari MA, Aguilar-Calvo P, Sklaviadis T, Papasavva-Stylianou P, Acutis PL, Acin C, Bossers A, Jacobs JG, Vaccari G, D'Agostino C, Chiappini B, Lantier F, Groschup MH, Agrimi U, Torres JM, Langeveld JPM (2019) Characterization of goat prions demonstrates geographical variation of scrapie strains in Europe and reveals the composite nature of prion strains. Sci Rep (in press)

\section{Publisher's Note}

Springer Nature remains neutral with regard to jurisdictional claims in published maps and institutional affiliations.
Ready to submit your research? Choose BMC and benefit from:

- fast, convenient online submission

- thorough peer review by experienced researchers in your field

- rapid publication on acceptance

- support for research data, including large and complex data types

- gold Open Access which fosters wider collaboration and increased citations

- maximum visibility for your research: over $100 \mathrm{M}$ website views per year

At BMC, research is always in progress.

Learn more biomedcentral.com/submissions 